\title{
Determinants of Preformed Collateral Vessels in the Human Heart without Coronary Artery Disease
}

\author{
Stefano F. de Marchi Steffen Gloekler Pascal Meier Tobias Traupe \\ Hélène Steck Stéphane Cook Rolf Vogel Christian Seiler \\ Department of Cardiology, University Hospital, Bern, Switzerland
}

For editorial comment see p. 195

\section{Key Words}

Coronary circulation - Collateral circulation •

Pathophysiology

\begin{abstract}
Background: Coronary collaterals protect myocardium jeopardized by coronary artery disease (CAD). Promotion of collateral circulation is desirable before myocardial damage occurs. Therefore, determinants of collateral preformation in patients without CAD should be elucidated. Methods: In 106 patients undergoing coronary angiography who were free of coronary stenoses, a total of 39 clinical test variables were collected. The coronary collateral flow index (CFI) was measured. Stepwise multiple linear regression analysis was performed after choosing a restricted number of candidates emerging from univariate testing. Separate multiple regression analyses were performed in patients with and without beta-blocker therapy. Results: Nine parameters were found to be possible determinants of CFI by univariate analysis: arterial hypertension (aHT), dyslipidemia, statins, diuretics, age, height, heart rate (HR), pulse pressure amplitude, and left ventricular end-diastolic pressure (LVEDP). After multiple regression analysis, a low $\mathrm{HR}$, absence of aHT, and elevated
\end{abstract}

LVEDP were significantly related to $C F I(F=5.31, p=0.002$, adjusted $r^{2}=0.12$ ). In patients without beta-blockers, a low $\mathrm{HR}$ and absence of aHT were independent predictors of CFI $\left(\mathrm{F}=8.03, \mathrm{p}<0.001, \mathrm{n}=50\right.$, adjusted $\left.\mathrm{r}^{2}=0.30\right)$. Conclusions: A low HR and absence of aHT are both related to collateral preformation in humans. We suppose that bradycardia favors fluid shear stress in coronary arteries, thus triggering collateral growth.

Copyright $\odot 2011$ S. Karger AG, Basel

\section{Introduction}

Cardiac disease is the most common cause of death worldwide, and coronary artery disease (CAD) is its major contributor [1]. CAD is characterized by mechanical and arrhythmic cardiac disorders as a consequence of myocardial ischemia. Successful treatment consists of restoring sufficient blood supply to the ischemic myocardium, the very aim of percutaneous coronary interventions and surgical revascularization. The promotion of coronary collaterals may become an alternative approach since these vessels represent natural bypasses able to sustain myocardial regions jeopardized by coronary lesions.

\section{KARGER}

Fax +41613061234 E-Mail karger@karger.ch www.karger.com

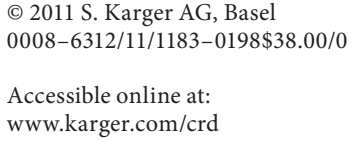

Christian Seiler, MD, FACC, FESC

Department of Cardiology

University Hospital Bern

CH-3010 Bern (Switzerland)

Tel. +41 31632 3693, E-Mail christian.seiler@insel.ch 
Walk-through angina pectoris, a probable feature of coronary collaterals [2], was first described in the 18th century by William Heberden [3], and CAD was later identified to be directly related to their formation [4]. Welldeveloped collaterals are associated with reduced mortality in patients with stable CAD [5] and with a reduced infarct size, the most important prognostic factor in patients with acute myocardial infarction [6]. Unfortunately, collateral formation varies considerably between individuals. In about one third of patients with stable CAD, collaterals are sufficiently developed to prevent myocardial ischemia during brief coronary occlusion [7].

Over centuries, it has been debated whether structural human coronary collaterals exist ubiquitously. In a postmortem study published in 1963, Fulton [8] elegantly resolved this issue using a new radiographic technique and demonstrated that a large number of arterio-arterial anastomoses can be found in all human hearts regardless of the presence or absence of cardiac disease. However, this ubiquity only applied to vessels smaller than $500 \mu \mathrm{m}$ in luminal diameter and mostly within the range of 40 $200 \mu \mathrm{m}$ [9]. Such small vessels may be considered nonfunctional because they are too resistant to flow and, therefore, not capable of transmitting sufficient perfusion pressure to the collateral-receiving artery. For adequate blood supply, anastomoses must enlarge and evolve into arteries that show all of the histological features of arterial conductance vessels. This process is referred to as arteriogenesis and includes remodeling of the adventitia and formation of a muscular tunica media providing the vessel with vasomotor capabilities such as sympathetic and flow-mediated dilation $[10,11]$. Coronary collateral arteriogenesis has been attributed exclusively to patients with CAD. However, in a study by Wustmann et al. [12], the presence of well-developed collaterals could be demonstrated in about one fourth of patients with normal coronary arteries, indicating that there are determinants of collateral pre-formation, i.e. determinants different from those of CAD-induced arteriogenesis.

The aim of this study in humans without CAD was to assess determinants of quantitatively measured collateral preformation.

\section{Methods}

\section{Patients}

106 patients who underwent quantitative collateral assessment but had normal coronary angiograms were included. All patients were referred for coronary angiography because of chest pain or a positive treadmill exercise test. A coronary angiogram was considered normal if the coronary artery tree was free of stenoses. Nonstenotic wall irregularities with $<10 \%$ diameter reduction were not an exclusion criterion. Patients with previous percutaneous coronary intervention, coronary bypass grafting, previous myocardial infarction, or acute coronary syndrome were excluded from the study. Since beta-blockers have a known constrictive effect on coronary collaterals [13-16], an additional analysis in patients with and without beta-blockers was performed. All patients gave written informed consent to participate in the study.

\section{Study Protocol}

The protocol was approved by the local ethics committee. As the authors of the manuscript we certify that we complied with the Principles of Ethical Publishing in the International Journal of Cardiology [17].

Left heart catheterization was performed using the right femoral approach. An intravenous bolus of 5,000 IU heparin and 2 puffs of oral isosorbide dinitrate was administered to all patients. A 5-Fr pigtail catheter was placed in the left ventricle (LV) for pressure measurement and biplane left ventricular angiography. A 5- to 6-Fr guiding catheter was then inserted into the ostium of the right (RCA) and left coronary arteries (LCA) for aortic pressure $\left(\mathrm{P}_{\mathrm{ao}}\right)$ measurement during coronary catheterization. A 0.014inch guide wire equipped with a pressure sensor at the tip (PressureWireP; RADI Medical Systems, Uppsala, Sweden) was inserted into the distal portion of the coronary tree after being zeroed and calibrated against the pressure derived from the guiding catheter. A 5-Fr pigtail catheter was placed in the right atrium via the right femoral vein for central venous pressure (CVP) measurements. Coronary collateral assessment was obtained during a proximal 1-min balloon occlusion of the coronary artery at a low inflation pressure (1-3 atm). Complete arterial occlusion was controlled by radiographic contrast injections, and distal coronary occlusion pressure $\left(\mathrm{P}_{\text {occl }}\right)$ was measured (fig. 1). Coronary collateral function was determined using simultaneously obtained mean $\mathrm{P}_{\mathrm{ao}}, \mathrm{P}_{\mathrm{occl}}$, and CVP [collateral flow index $(\mathrm{CFI})=\left(\mathrm{P}_{\mathrm{occl}}-\right.$ $\left.\mathrm{CVP}) /\left(\mathrm{P}_{\mathrm{ao}}-\mathrm{CVP}\right)\right][18,19]$. In 37 patients, a single 18 - or $12-\mu \mathrm{g}$ bolus of adenosine was injected into the LCA or RCA, respectively. The fractional flow reserve was calculated as the ratio of the mean distal coronary pressure to the mean $\mathrm{P}_{\mathrm{a}}$ under maximal hyperemia.

\section{Clinical and Hemodynamic Patient Data}

Clinical data were assessed focusing on current symptoms of cardiac disease, cardiovascular risk factors, personal history of cardiovascular disease, and current medication. In particular, arterial hypertension and diabetes mellitus were defined according to international diagnosis guidelines. Patients underwent a physical examination and standard laboratory blood tests, including lipid profiling. Hemodynamic measurements included: mean systemic blood pressure, blood pressure amplitude and heart rate under resting conditions prior to cardiac catheterization, measurement of left ventricular end-diastolic pressure (LVEDP), and peak aortic gradient during catheterization. The left ventricular ejection fraction was assessed quantitatively from biplane ventriculograms. A total of 39 test variables were collected in all patients. 

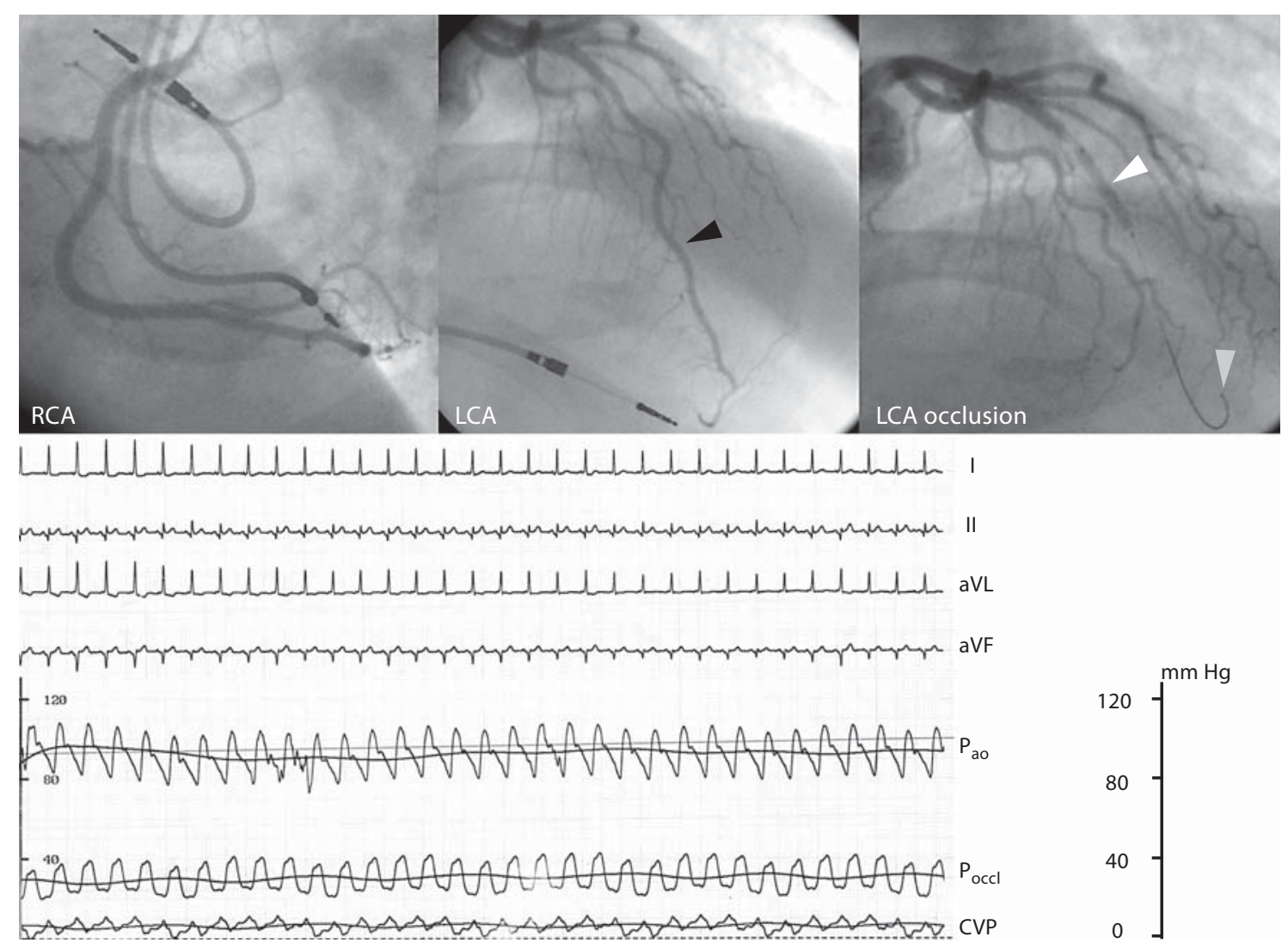

Fig. 1. Angiographic images of a patient subjected to coronary angiography because of chest pain. The RCA and LCA were normal. The right upper panel shows a balloon occlusion of the left anterior descending artery (white arrowhead) and the distally placed guide wire equipped with a pressure sensor (gray arrowhead). The same vessel is well visible before occlusion (black arrowhead). The lower panel shows the 3 pressure curves, each as phasic and mean tracing, and 4 peripheral ECG leads on top (I, II, aVL, aVF). The occlusive pressure was well above the CVP, yielding a CFI of 0.319 . Note that the collateral-derived perfusion was sufficient to prevent ECG ST segment elevations.

\section{Statistical Analyses}

In order to assess the independent predictors of CFI, a 2-step approach was chosen:

In the first step, univariate analysis comparing all available clinical test variables (see above) with CFI as the dependent variable was performed to restrict the choice of candidates for further multivariate testing. Univariate testing consisted of linear regression analyses for metric and unpaired Student's t tests for dichotomous, categorical test variables. A threshold of $p<0.10$ was used to select candidates for multivariate analysis. A stepwise multiple linear regression model was chosen to determine the independent predictors of CFI in all patients.

In the second step, patients were divided into 2 groups according to the current intake of beta-blockers. The variables found to be significant predictors in the overall multivariate analysis were entered into a standard multiple regression model in both groups.

Dichotomous variables were used as dummy variables in all multiple regression analyses. Assumption testing was performed following each completion of a multiple regression calculation us- ing the following 3 statistical procedures: (1) a Durbin-Watson test to check the assumption of independence of the residuals, with a value between 1.5 and 2.5 being mandatory; (2) colinearity statistics to exclude multicolinearity between the test variables, including all variables not entered into the stepwise procedure or excluded in the standard procedure (a tolerance value $>0.10$ was defined as mandatory), and (3) a Kolmogorov-Smirnov (KS) test of the standard residuals requiring $\mathrm{p}>0.05$ to satisfy the assumption of normality of the residuals.

The results of the overall regression fittings were calculated, including the intercept and standardized coefficients of the multiple regression equation $(\beta)$, adjusted coefficient of determination (adjusted $\mathrm{r}^{2}$ ), and ANOVA $\mathrm{F}$ and $\mathrm{p}$ values of the overall regression model. Only variables with significant nonzero slopes in the regression equation were considered independent predictors of CFI. Unless otherwise indicated, $\mathrm{p}<0.05$ was statistically significant. All analyses were performed using the SPSS 15.0 software package (SPSS Inc., Chicago, Ill., USA) and Prism GraphPad 5 (GraphPad Software, La Jolla, Calif., USA). 
Table 1. Patient characteristics

\begin{tabular}{|c|c|}
\hline \multicolumn{2}{|l|}{ Hemodynamic parameters } \\
\hline CFI & $0.177 \pm 0.100(0.012-0.625)$ \\
\hline Fractional flow reserve $(n=37)$ & $0.94 \pm 0.05(0.76-1.00)$ \\
\hline Age, years & $60 \pm 10(20-86)$ \\
\hline Weight, kg & $79 \pm 16(44-124)$ \\
\hline Height, $\mathrm{cm}$ & $170 \pm 10(145-192)$ \\
\hline Body mass index & $27 \pm 5(19-44)$ \\
\hline Mean blood pressure, $\mathrm{mm} \mathrm{Hg}$ & $95 \pm 15(67-151)$ \\
\hline Pulse pressure amplitude, $\mathrm{mm} \mathrm{Hg}$ & $55 \pm 19(2-11)$ \\
\hline LVEDP, $\mathrm{mm} \mathrm{Hg}$ & $10 \pm 5(1-28)$ \\
\hline Peak aortic gradient, $\mathrm{mm} \mathrm{Hg}$ & $4 \pm 6(0-48)$ \\
\hline Heart rate, bpm & $70 \pm 12(48-115)$ \\
\hline LV ejection fraction, $\%$ & $66 \pm 10(20-89)$ \\
\hline \multicolumn{2}{|l|}{ Laboratory findings } \\
\hline Glucose, $\mathrm{mmol} / \mathrm{l}$ & $5.98 \pm 1.78(3.62-20.00)$ \\
\hline Triglycerides, mmol/l & $1.77 \pm 1.44(0.46-12.40)$ \\
\hline Total cholesterol, $\mathrm{mmol} / \mathrm{l}$ & $5.35 \pm 0.95(3.62-7.89)$ \\
\hline HDL cholesterol, mmol/l & $1.47 \pm 0.43(0.48-3.06)$ \\
\hline LDL cholesterol, mmol/l & $3.52 \pm 0.91(1.34-5.92)$ \\
\hline HDL/LDL ratio & $3.95 \pm 1.37(1.67-11.04)$ \\
\hline Creatinine, $\mathrm{mmol} / \mathrm{l}$ & $80.4 \pm 20.9(45.0-138.0)$ \\
\hline Potassium, mmol/l & $4.00 \pm 0.35(2.70-4.90)$ \\
\hline Sodium, $\mathrm{mmol} / \mathrm{l}$ & $140 \pm 2(135-145)$ \\
\hline Hemoglobin, mmol/l & $138 \pm 14(9-170)$ \\
\hline Leucocytes, $\times 10^{9} / 1$ & $7.34 \pm 7.03(4-74)$ \\
\hline Platelets, $\times 10^{9} / 1$ & $242 \pm 61(146-414)$ \\
\hline \multicolumn{2}{|l|}{ General/clinical characteristics } \\
\hline Male gender & $65(61.3 \%)$ \\
\hline Diabetes mellitus & $8(7.5 \%)$ \\
\hline Angina pectoris & $44(41.5 \%)$ \\
\hline Arterial hypertension & $56(52.8 \%)$ \\
\hline Smoker & $28(26.4 \%)$ \\
\hline Body mass index $>30$ & $26(24.5 \%)$ \\
\hline Dyslipidemia & $48(45.3 \%)$ \\
\hline Family history positive for CAD & $36(34 \%)$ \\
\hline \multicolumn{2}{|l|}{ Cardiovascular medication } \\
\hline Calcium channel blockers & $15(14.2 \%)$ \\
\hline Beta-blockers & $51(48.1 \%)$ \\
\hline Nitrates & $19(17.9 \%)$ \\
\hline Aspirin & $57(53.8 \%)$ \\
\hline Clopidogrel & $2(1.9 \%)$ \\
\hline Statins & $23(21.7 \%)$ \\
\hline ACE inhibitors & $18(17 \%)$ \\
\hline Angiotensin receptor blockers & $11(10.4 \%)$ \\
\hline Diuretics & $19(17.9 \%)$ \\
\hline
\end{tabular}

Metric variables are given as means \pm standard deviation (range). Categorical variables are given as numbers. ACE $=\mathrm{An}$ giotensin-converting enzyme; $\mathrm{HDL}=$ high-density lipoprotein; $\mathrm{LDL}=$ low-density lipoprotein.
Table 2. Linear regression analyses between the different metric test variables and CFI

\begin{tabular}{lrrrll}
\hline Variables & $\begin{array}{l}\text { Inter- } \\
\text { cept }\end{array}$ & Slope & $\mathrm{r}$ & $\mathrm{r}^{2}$ & $\mathrm{p}$ \\
\hline Age & 0.28 & -0.0017 & -0.17 & 0.03 & $0.07^{\mathrm{a}}$ \\
Weight & 0.11 & 0.0008 & 0.13 & 0.02 & 0.20 \\
Height & -0.12 & 0.0017 & 0.17 & 0.03 & $0.08^{\mathrm{a}}$ \\
Body mass index & 0.15 & 0.0011 & 0.05 & 0.001 & 0.58 \\
Mean blood pressure & 0.25 & -0.0008 & -0.12 & 0.01 & 0.23 \\
Pulse pressure amplitude & 0.22 & -0.0009 & -0.16 & 0.03 & $0.09^{\mathrm{a}}$ \\
LVEDP & 0.13 & 0.0047 & 0.24 & 0.06 & $0.02^{\mathrm{a}}$ \\
Peak aortic gradient & 0.17 & 0.0024 & 0.15 & 0.02 & 0.15 \\
Heart rate & 0.31 & -0.0020 & -0.23 & 0.05 & $0.02^{\mathrm{a}}$ \\
LV ejection fraction & 0.11 & 0.0010 & 0.11 & 0.01 & 0.28 \\
Glucose & 0.14 & 0.0057 & 0.10 & 0.01 & 0.32 \\
Triglycerides & 0.16 & 0.0062 & 0.09 & 0.01 & 0.37 \\
Total cholesterol & 0.15 & 0.0033 & 0.03 & 0.001 & 0.75 \\
HDL cholesterol & 0.19 & -0.0142 & -0.06 & 0.004 & 0.53 \\
LDL cholesterol & 0.16 & 0.0048 & 0.05 & 0.002 & 0.66 \\
HDL/LDL ratio & 0.16 & 0.0042 & 0.06 & 0.003 & 0.56 \\
Creatinine & 0.17 & -0.00003 & -0.007 & 0.0001 & 0.94 \\
Potassium & 0.27 & -0.0241 & 0.09 & 0.007 & 0.40 \\
Sodium & 1.40 & -0.0086 & 0.21 & 0.04 & 0.12 \\
Hemoglobin & 0.13 & 0.0003 & 0.04 & 0.002 & 0.69 \\
Leucocytes & 0.18 & -0.0001 & -0.08 & 0.006 & 0.45 \\
Platelets & 0.18 & -0.000003 & 0.02 & 0.003 & 0.87 \\
\hline
\end{tabular}

$\mathrm{HDL}=$ High-density lipoprotein $\mathrm{LDL}=$ low-density lipoprotein. ${ }^{a}$ Variables selected for further multivariate analysis.

\section{Results}

\section{Univariate Analysis}

A total of 106 patients were included in the study. Their clinical baseline characteristics are listed in table 1 . The univariate comparison between the initial test variables and CFI are listed in table 2 for continuous data and in table 3 for categorical data. Based on the selection criteria described above, the following 9 variables were chosen for further multivariate testing: arterial hypertension, dyslipidemia, intake of statins, intake of diuretics, age, height, heart rate, pulse pressure amplitude, and LVEDP.

\section{Multivariate Analysis}

The subsequent stepwise multiple regression analysis could be performed in 101 patients. Five patients were omitted due to missing values for 1 or more variables. The results of the stepwise regression are listed in table 4 .

A significant overall model was found $(\mathrm{F}=5.31, \mathrm{p}=$ $0.002, \mathrm{n}=101)$. The adjusted $\mathrm{r}^{2}$ value was 0.12 . The LVEDP $(\beta=0.264, p=0.008)$ was positively related to CFI, where- 
Table 3. Independent group comparisons of CFI means between different categorical test variables

\begin{tabular}{lcccc}
\hline Variable & $\mathrm{n}$ (no/yes) & CFI (no) & CFI (yes) & p value \\
\hline Male gender & $41 / 65$ & $0.175 \pm 0.085$ & $0.175 \pm 0.108$ & 0.96 \\
Angina pectoris & $62 / 44$ & $0.164 \pm 0.100$ & $0.190 \pm 0.096$ & 0.18 \\
Diabetes mellitus & $98 / 8$ & $0.173 \pm 0.101$ & $0.203 \pm 0.064$ & 0.41 \\
Arterial hypertension & $50 / 56$ & $0.192 \pm 0.105$ & $0.160 \pm 0.092$ & $0.09^{\mathrm{a}}$ \\
Smoker & $78 / 28$ & $0.183 \pm 0.102$ & $0.153 \pm 0.087$ & 0.18 \\
Body mass index $>30$ & $80 / 26$ & $0.171 \pm 0.091$ & $0.189 \pm 0.121$ & 0.42 \\
Dyslipidemia & $58 / 48$ & $0.159 \pm 0.086$ & $0.195 \pm 0.110$ & $0.06^{\mathrm{a}}$ \\
Family history positive for CAD & $70 / 36$ & $0.172 \pm 0.096$ & $0.182 \pm 0.106$ & 0.62 \\
Calcium channel blockers & $91 / 15$ & $0.178 \pm 0.102$ & $0.157 \pm 0.075$ & 0.44 \\
Beta-blockers & $55 / 51$ & $0.183 \pm 0.105$ & $0.166 \pm 0.093$ & 0.39 \\
Nitrates & $87 / 19$ & $0.174 \pm 0.092$ & $0.180 \pm 0.131$ & 0.81 \\
Aspirin & $49 / 57$ & $0.183 \pm 0.110$ & $0.169 \pm 0.0897$ & 0.48 \\
Clopidogrel & $104 / 2$ & $0.174 \pm 0.099$ & $0.220 \pm 0.114$ & 0.52 \\
Statins & $83 / 23$ & $0.165 \pm 0.101$ & $0.211 \pm 0.084$ & $0.05^{\mathrm{a}}$ \\
ACE inhibitors & $88 / 18$ & $0.173 \pm 0.100$ & $0.185 \pm 0.097$ & 0.64 \\
Angiotensin receptor antagonists & $95 / 11$ & $0.179 \pm 0.102$ & $0.140 \pm 0.062$ & 0.22 \\
Diuretics & $87 / 19$ & $0.183 \pm 0.102$ & $0.140 \pm 0.079$ & $0.09^{\mathrm{a}}$ \\
\hline
\end{tabular}

CFI values are given as means \pm standard deviation. $\mathrm{ACE}=$ Angiotensin-converting enzyme.

${ }^{a}$ Variables selected for further multivariate analysis.

Table 4. Results of the multiple regression analyses in all patients and in the subgroups with and without betablockers

\begin{tabular}{|c|c|c|c|c|c|c|}
\hline Variable & \multicolumn{2}{|c|}{ All patients } & \multicolumn{2}{|c|}{ No beta-blockers } & \multicolumn{2}{|c|}{ Beta-blockers } \\
\hline Patients, $\mathrm{n}$ & \multicolumn{2}{|l|}{101} & \multicolumn{2}{|l|}{50} & \multicolumn{2}{|l|}{51} \\
\hline \multicolumn{7}{|l|}{ Overall regression model } \\
\hline Adjusted $\mathrm{r}^{2}$ & 0.12 & & 0.30 & & 0.07 & \\
\hline $\mathrm{F}$ & 5.31 & & 8.03 & & 2.17 & \\
\hline \multirow[t]{2}{*}{$\mathrm{p}$ value } & $0.002^{\mathrm{a}}$ & & $<0.001^{\mathrm{a}}$ & & 0.11 & \\
\hline & $\beta$ & $\mathrm{p}$ value & $\beta$ & $\mathrm{p}$ value & $\beta$ & $\mathrm{p}$ value \\
\hline \multicolumn{7}{|l|}{ Coefficients } \\
\hline Constant & - & $<0.001^{\mathrm{a}}$ & - & $<0.001$ & - & 0.51 \\
\hline LVEDP & 0.264 & $0.008^{\mathrm{a}}$ & 0.234 & 0.06 & 0.376 & $0.014^{\mathrm{a}}$ \\
\hline Arterial hypertension & -0.216 & $0.027^{\mathrm{a}}$ & -0.355 & $0.006^{\mathrm{a}}$ & -0.106 & 0.46 \\
\hline Heart rate & -0.201 & $0.036^{\mathrm{a}}$ & -0.468 & $<0.001^{\mathrm{a}}$ & 0.104 & 0.47 \\
\hline
\end{tabular}

a Statistically significant values.

as arterial hypertension $(\beta=-0.216, \mathrm{p}=0.027)$ and heart rate $(\beta=-0.201, p=0.036)$ were negatively related to CFI. Assumption testing yielded satisfactory results (DurbinWatson 2.38, tolerance $>0.95$ for all test variables, KS p $>$ $0.17)$.

Fifty-two patients took beta-blockers at the time of inclusion, and 51 patients did not take beta-blockers.
LVEDP, arterial hypertension, and heart rate were entered into a standard multiple regression analysis. The results are summarized in table 4 .

In patients with beta-blockers the overall model did not show a significant $\mathrm{p}$ value by ANOVA testing $(\mathrm{F}=$ $2.17, \mathrm{p}=0.11, \mathrm{n}=51$ ), and the adjusted $\mathrm{r}^{2}$ value was 0.07 , although LVEDP was significantly related to CFI $(\beta=$ 
$0.376, p=0.01)$. Neither arterial hypertension $(\beta=-0.106$, $\mathrm{p}=0.46)$ nor heart rate $(\beta=0.104, \mathrm{p}=0.47)$ was related to CFI. Assumptions were satisfied (Durbin-Watson 1.61, tolerance $>0.86$ for all test variables, KS $p>0.10$ ).

In patients without beta-blockers, the regression model was significant $(\mathrm{F}=8.03, \mathrm{p}<0.001, \mathrm{n}=50)$ and yielded an adjusted $r^{2}$ value of 0.30 . Heart rate $(\beta=-0.468, p<$ $0.001)$ and arterial hypertension $(\beta=-0.355, \mathrm{p}=0.006)$ emerged as independent predictors of CFI. LVEDP had no significant $p$ value $(\beta=0.234, p=0.06)$. The mandatory values in assumption testing were achieved (Durbin-Watson 1.74 , tolerance $>0.94$ for all test variables, $\mathrm{KS} \mathrm{p}>0.17$ ).

\section{Discussion}

The present study in patients with normal coronary arteries found a low heart rate, absence of arterial hypertension, and a high left ventricular filling pressure to be 'independent' determinants of preformed functional collateral vessels. There appear to be mechanisms other than hemodynamically relevant coronary stenoses in adult life capable of adapting collateral function in the human heart. In the subgroup of patients without beta-blockers, close to one third of the collateral flow variability could be explained by 2 clinical factors: resting heart rate and arterial hypertension. The present study reveals determinants of collateral function that may have been masked in a previous study in CAD patients [7], possibly due to the strong remodeling influence of stenoses and differences in pharmacologic treatment.

\section{Low Heart Rate as a Promoter of Fluid Shear Stress}

Among the 3 determinants, heart rate is of particular interest because the finding is in line with the pathogenic model of arteriogenesis. There is compelling evidence that arteriogenesis is triggered by fluid shear stress at the endothelial wall $[20,21]$. Fluid shear stress is known to invoke endothelial activation, although the exact biomechanical cascade of events is not exactly known. The production of chemoattractants in the context of arteriogenic triggering leads to endothelial binding of circulating monocytes and to perivascular accumulation of macrophages, both involved in the vascular remodeling process. In patients with coronary stenoses, blood flow is driven by pressure gradients between collateral-supplying and collateral-receiving segments. Consequently, fluid shear stress is increased inside the collateral channels. As a result, we found that stenosis severity was the most important determinant of collateral flow in a multivariate

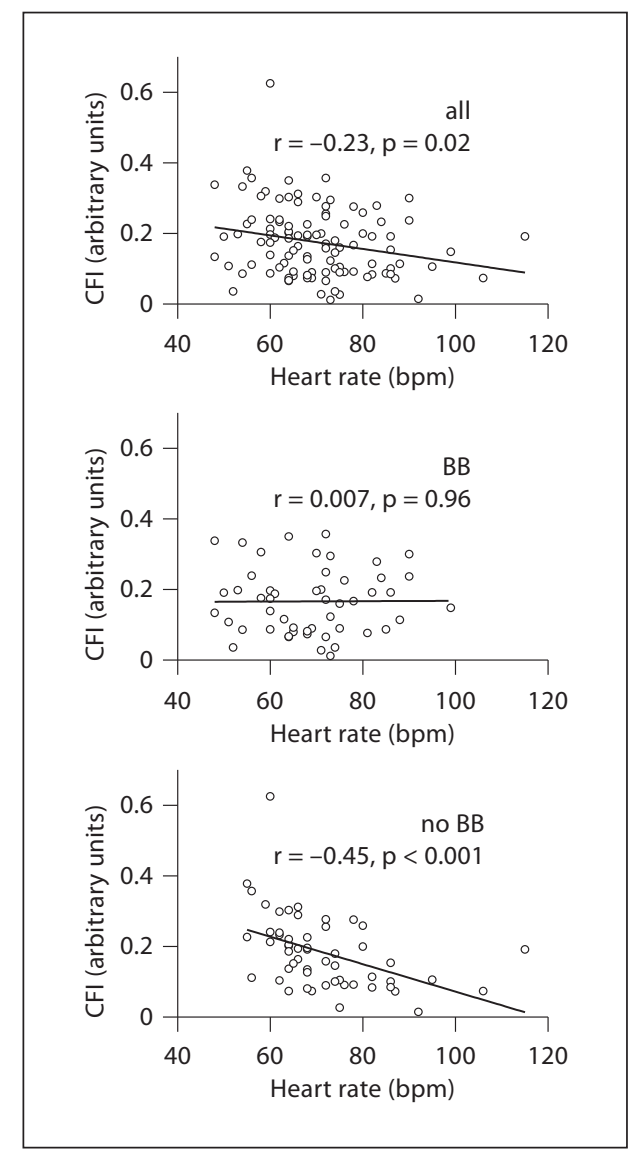

Fig. 2. Linear regression analyses of the heart rate and CFI. There was an inverse relationship in all patients (upper panel, $\mathrm{y}=0.31-$ $0.0019 \mathrm{x})$. In patients taking beta-blockers (BB; middle panel), this relationship disappeared, whereas it was accentuated in patients without beta-blockers (no BB; lower panel, $y=0.46-0.0039 x$ ).

analysis in 450 patients with CAD [7]; this finding quantitatively confirmed recent and historical clinical observations. It is not known to what extent such interarterial pressure gradients can be built up in the absence of coronary stenoses. We speculate that there is sufficient fluid shear stress to support arteriogenesis, depending on the in- and outlet of the collaterals, the latter of which gives rise to a pressure gradient along a collateral path of a few millimeters of mercury. How does heart rate play a biologically reasonable role in the context of fluid shear stress? The diastolic period compared to the systolic period is affected overproportionally by heart rate changes. Since coronary flow is predominantly diastolic, the duration of flow, and therefore fluid shear stress and endothelial activation, is inversely related to heart rate. Bradycardia-related stimulation of collateral growth has been 
demonstrated in experimental animal models [22, 23] and observed angiographically in humans with CAD [24].

Thus, it seems that heart rate and collateral flow are causally related. Heart rate reduction might therefore be an interesting concept for the promotion of collateral growth in humans. Prediction calculation using the results of the present study shows that a decrease in heart rate from 80 to $60 \mathrm{bpm}$ in nonhypertensive patients without beta-blockers is associated with an increase in CFI from 0.18 to 0.26 . In patients receiving beta-blockers, the positive effect of bradycardia on collateral function is probably annihilated by concomitant collateral vasoconstriction (fig. 2).

\section{Arterial Hypertension: Hindering Arteriogenic Remodeling Activities?}

The present study consistently shows that in individuals without $\mathrm{CAD}$ arterial hypertension is inversely related to coronary collateral function. The role of arterial hypertension in coronary collateral formation has been discussed controversially in the past. In patients with CAD, Kyriakides et al. [25] found that well-developed collaterals are found more frequently in hypertensive patients than in nonhypertensive patients. On the other hand, Koerselman et al. [26] reported an inverse relation between collaterals and blood pressure. In both studies, collateral assessment was based on visual inspection of coronary angiograms without vessel occlusion, a method known to represent a crude estimate of collateral flow and one particularly lacking sensitivity for small vessels compared to quantitative occlusive pressure measurements [27]. Additionally, predictors other than stenosis severity are difficult to extract in a CAD population even if quantitative collateral measurements are performed [7]. The present study has none of these limitations. One can only speculate about the underlying pathophysiologic mechanisms. Several structural and functional changes are typically encountered in hypertensive heart disease. These include: medial thickening and perivascular fibrosis in myocardial arteriolar vessels [28], increased external vessel compression, rarefaction of the microcirculation [28, 29], diminished adenosine-induced vasodilation capacity [30], and retarded myocardial relaxation [31]. The arteriogenic process of arterial remodeling, especially the renewal of adventita to allow outward vessel growth, may thus be hampered by arterial hypertension. In addition, arteriolar luminal narrowing and obliteration, vasomotor abnormalities, and diastolic LV dysfunction may all impede fluid shear stress-triggered growth activation through hemodynamic flow impairment.
Taking the abovementioned considerations together, it can be speculated that the excess mortality of myocardial infarction in the presence of arterial hypertension is partly attributable to the reduced presence of functional coronary collaterals with larger infarcts in the course of coronary atherosclerotic occlusion [32].

\section{LVEDP and Collateral Assessment: Independent Variables?}

Physiologically, we do not consider LVEDP to be an independent predictor of collateral flow, although it was statistically significant in the multivariate analysis in all patients. The opposite influence of high LVEDP and arterial hypertension on CFI is contradictory since left ventricular diastolic dysfunction and increased LVEDP are common in arterial hypertension. The influence of left ventricular diastolic wall stress (and thus LVEDP) on coronary wedge pressure measurements has been studied previously [33]. Collateral flow tends to be overestimated when the LVEDP during coronary occlusion exceeds 27 $\mathrm{mm} \mathrm{Hg}$ and collateral function is insufficient to prevent ECG signs of ischemia. It has been suggested that collapse of the microvascular bed at a low arterial (occlusion) pressure may disconnect the arterial vascular bed from the venous vascular bed, thus potentially leading to zero flow despite a positive arteriovenous pressure difference $[34,35]$. Although this phenomenon is rarely encountered [33], it seems to be sufficient to establish the statistical relationship with CFI found in the present study. A certain a priori dependence between CFI measurement and LVEDP must therefore be assumed. Thus, we do not consider it to reflect a real determinant of collateral flow.

\section{Unrelated Variables}

Interestingly, other conditions known to lead to myocardial microvascular disease, such as diabetes mellitus [36], dyslipidemia [37], and smoking [38], were all found to be unrelated to CFI. The analysis was unlikely to reveal any role of diabetes mellitus because of the remarkably low number of patients in this study (7.5\%). We suppose that only a few patients with diabetes who were subjected to coronary angiography showed normal coronary arteries and could therefore be included in the study. CAD populations under investigation at our institution usually reveal diabetes mellitus at a rate exceeding $15 \%$, but a role in collateral formation has never been found $[5,7]$. In addition, is has been shown that microvascular disease is related to hyperglycemia rather than to the presence or absence of diabetes mellitus per se [36]. 
Dyslipidemia and use of statins were both entered into the stepwise regression analysis because they consistently emerged in the univariate analyses, but they were then found not to be independent predictors in multivariate testing. The natural influence of dyslipidemia on collateral channels may have been masked by statins. It is possible, however, that this study was underpowered for the assessment of the role of dyslipidemia in collateral formation.

Smoking has also been associated with myocardial microvascular disease [38]. Although $26 \%$ of our study population consisted of current smokers, the lack of any relation to CFI was consistent.

\section{Nonobserved Variables}

According to the criteria of Cohen et al. [39], a relation yielding an $\mathrm{r}^{2}$ value of 0.30 can be considered a 'strong relationship' in multiple regression analysis. Considering that pressure measurements are occasionally prone to baseline shifts, the remaining scatter is surprisingly low but still sufficient to expect that other, nonobserved determinants of collateral formation exist. We assume that genetic factors play an important role and are likely to fill part of the gap. Very recently, we identified 203 and 56 genes that were related to CFI in patients with and without CAD, respectively [40]. Seventy-six of these genes belonged to the 4 following biological signaling pathways: angiogenesis, integrin, platelet-derived growth factor, and transforming growth factor- $\beta$. In the present study, however, we renounced to include a genetic analysis because it would have severely hampered the explanatory power of the multivariate statistics due to an excessive number of test variables compared to the overall population size.

\section{Limitations}

An important limitation of the present study relates to nonobserved variables. As mentioned above, a genetic analysis was not included in this study. In addition, no data on LV mass were collected by routine echocardiography. Substituting arterial hypertension by a metric variable such as LV mass might have provided more insight into mechanisms of collateral deprivation in hypertensive patients. Similarly, no data on physical exercise and glycosylated hemoglobin were collected.

Two statistical outliers were found in multiple regression analysis. A 69-year-old woman who suffered from intermittent but rarely occurring atrial fibrillation was subjected to coronary angiography. The coronary arteries were normal. At the time of cardiac catheterization, atrial

fibrillation was present, and the heart rate was $115 \mathrm{bpm}$. This condition could not be considered to reflect her habitual cardiac status. In a 67-year-old man suffering from myotonic dystrophy, intracoronary pressure measurement revealed an extraordinarily high collateral flow $(\mathrm{CFI}=0.63)$. The statistical results, however, were not relevantly altered after tentative exclusion of the cases. On the contrary, the $r^{2}$ value of the multiple regression in patients without beta-blockers exceeded 0.40 after exclusion, and statistical outlier diagnostics did not show a relevant influence on the overall multiple regression. In order to present unfiltered data, we decided not to exclude these cases.

\section{Conclusions}

We conclude that there are at least 2 factors in adult life in the absence of coronary stenoses that influence collateral formation in the human heart: a low heart rate and the absence of arterial hypertension.

\section{Acknowledgement}

This study was supported by a grant from the Swiss National Science Foundation (No. 3200BO-112341/1).

\section{Conflict of Interest}

None.

References

Cardiology 2011;118:198-206

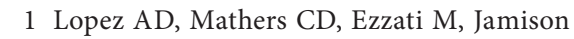
DT, Murray CJ: Global and regional burden of disease and risk factors, 2001: systematic analysis of population health data. Lancet 2006;367:1747-1757.

-2 Togni M, Gloekler S, Meier P, de Marchi SF, Rutz T, Steck H, Traupe T, Seiler C: Instantaneous coronary collateral function during supine bicycle exercise. Eur Heart J 2010;31: 2148-2155

3 Willius F, Keys T: Classics of Cardiology. New York, Dover, 1941.

4 West S: The anastomosis of the coronary arteries. Lancet 1883;121:945-946.

5 Meier P, Gloekler S, Zbinden R, Beckh S, de Marchi SF, Zbinden S, Wustmann K, Billinger $\mathrm{M}$, Vogel $\mathrm{R}$, Cook $\mathrm{S}$, Wenaweser $\mathrm{P}$, Togni M, Windecker S, Meier B, Seiler C: Beneficial effect of recruitable collaterals: a 10 -year follow-up study in patients with stable coronary artery disease undergoing quantitative collateral measurements. Circulation 2007;116:975-983. 
6 Kodama K, Kusuoka H, Sakai A, Adachi T, $>16$ Traverse JH, Altman JD, Kinn J, Duncker DJ, Hasegawa S, Ueda Y, Mishima M, Hori M, Kamada T, Inoue M, Hirayama A: Collateral channels that develop after an acute myocardial infarction prevent subsequent left ventricular dilation. J Am Coll Cardiol 1996;27: 1133-1139.

$\checkmark 7$ Pohl T, Seiler C, Billinger M, Herren E, Wustmann K, Mehta H, Windecker S, Eberli FR, Meier B: Frequency distribution of collateral flow and factors influencing collateral channel development: functional collateral channel measurement in 450 patients with coronary artery disease. J Am Coll Cardiol 2001;38:1872-1878.

$\checkmark 8$ Fulton WF: Arterial anastomoses in the coronary circulation. 1. Anatomical features in normal and diseased hearts demonstrated by stereoarteriography. Scott Med J 1963;8: 420-434.

$\checkmark 9$ Fulton WF: Arterial anastomoses in the coronary circulation. 2. Distribution, enumeration and measurement of coronary arterial anastomoses in health and disease. Scott Med J 1963;8:466-474.

-10 de Marchi SF, Schwerzmann M, Billinger M, Windecker S, Meier B, Seiler C: Sympathetic stimulation using the cold pressor test increases coronary collateral flow. Swiss Med Wkly 2001;131:351-356.

- 11 Werner GS, Fritzenwanger M, Prochnau D, Schwarz G, Ferrari M, Aarnoudse W, Pijls NH, Figulla HR: Determinants of coronary steal in chronic total coronary occlusions donor artery, collateral, and microvascular resistance. J Am Coll Cardiol 2006;48:51-58.

12 Wustmann K, Zbinden S, Windecker S, Meier B, Seiler C: Is there functional collateral flow during vascular occlusion in angiographically normal coronary arteries? Circulation 2003;107:2213-2220.

-13 Billinger M, Raeber L, Seiler C, Windecker S, Meier B, Hess OM: Coronary collateral perfusion in patients with coronary artery disease: effect of metoprolol. Eur Heart J 2004; 25:565-570.

-14 Kyriakides ZS, Kolettis T, Antoniadis A, Nikolaou N, Sbarouni E, Tzanalaridou E, Kremastinos DT: Beta-adrenergic blockade decreases coronary collateral blood flow in patients with coronary artery disease. Cardiovasc Drugs Ther 1998;12:551-559.

-15 Sato M, Harding SE, Poole-Wilson PA: Betablockers, myocardial ischaemia and collateral circulation. Eur Heart J 2004;25:537539.
Bache RJ: Effect of beta-adrenergic receptor blockade on blood flow to collateral-dependent myocardium during exercise. Circulation 1995;91:1560-1567.

17 Shewan LG, Coats JS: Ethics in the authorship and publishing of scientific articles. Int J Cardiol 2010;144:1-2.

18 Matsuo H, Watanabe S, Kadosaki T, Yamaki T, Tanaka S, Miyata S, Segawa T, Matsuno Y, Tomita M, Fujiwara H: Validation of collateral fractional flow reserve by myocardial perfusion imaging. Circulation 2002;105: 1060-1065.

19 Seiler C, Fleisch M, Garachemani A, Meier B: Coronary collateral quantitation in patients with coronary artery disease using intravascular flow velocity or pressure measurements. J Am Coll Cardiol 1998;32:12721279.

20 Grundmann S, Piek JJ, Pasterkamp G, Hoefer IE: Arteriogenesis: basic mechanisms and therapeutic stimulation. Eur J Clin Invest 2007;37:755-766.

21 Heil M, Schaper W: Insights into pathways of arteriogenesis. Curr Pharm Biotechnol 2007; $8: 35-42$

22 Lamping KG, Zheng W, Xing D, Christensen LP, Martins J, Tomanek RJ: Bradycardia stimulates vascular growth during gradual coronary occlusion. Arterioscler Thromb Vasc Biol 2005;25:2122-2127.

23 Wright AJ, Hudlicka O: Capillary growth and changes in heart performance induced by chronic bradycardial pacing in the rabbit. Circ Res 1981;49:469-478.

24 Bishop AH, Samady H: Fractional flow reserve: critical review of an important physiologic adjunct to angiography. Am Heart J 2004;147:792-802.

-25 Kyriakides ZS, Kremastinos DT, Michelakakis NA, Matsakas EP, Demovelis T, Toutouzas PK: Coronary collateral circulation in coronary artery disease and systemic hypertension. Am J Cardiol 1991;67:687-690.

-26 Koerselman J, de Jaegere PP, Verhaar MC, van der Graaf Y, Grobbee DE: High blood pressure is inversely related with the presence and extent of coronary collaterals. J Hum Hypertens 2005;19:809-817.

-27 Werner GS, Ferrari M, Heinke S, Kuethe F, Surber R, Richartz BM, Figulla HR: Angiographic assessment of collateral connections in comparison with invasively determined collateral function in chronic coronary occlusions. Circulation 2003;107:1972-1977.
28 Mundhenke M, Schwartzkopff B, Strauer BE: Structural analysis of arteriolar and myocardial remodelling in the subendocardial region of patients with hypertensive heart disease and hypertrophic cardiomyopathy. Virchows Arch 1997;431:265-273.

29 Indermuhle A, Vogel R, Meier P, Wirth S, Stoop R, Mohaupt MG, Seiler C: The relative myocardial blood volume differentiates between hypertensive heart disease and athlete's heart in humans. Eur Heart J 2006;27: 1571-1578.

30 Pijls NH, De Bruyne B: Coronary Pressure. Dordrecht, Kluwer, 2000.

>31 Mandinov L, Eberli FR, Seiler C, Hess OM: Diastolic heart failure. Cardiovasc Res 2000; 45:813-825.

32 Gustafsson F, Kober L, Torp-Pedersen C, Hildebrandt P, Ottesen MM, Sonne B, Carlsen J: Long-term prognosis after acute myocardial infarction in patients with a history of arterial hypertension - TRACE study group. Eur Heart J 1998;19:588-594.

-33 de Marchi SF, Oswald P, Windecker S, Meier B, Seiler C: Reciprocal relationship between left ventricular filling pressure and the recruitable human coronary collateral circulation. Eur Heart J 2005;26:558-566.

34 Downey JM, Kirk ES: Inhibition of coronary blood flow by a vascular waterfall mechanism. Circ Res 1975;36:753-760.

35 Spaan J: Coronary Blood Flow - Mechanics, Distribution, and Control. Dordrecht, Kluwer, 1991.

>36 Di Carli MF, Janisse J, Grunberger G, Ager J: Role of chronic hyperglycemia in the pathogenesis of coronary microvascular dysfunction in diabetes. J Am Coll Cardiol 2003;41: 1387-1393.

>37 Kaufmann PA, Gnecchi-Ruscone T, Schafers KP, Luscher TF, Camici PG: Low density lipoprotein cholesterol and coronary microvascular dysfunction in hypercholesterolemia. J Am Coll Cardiol 2000;36:103-109.

>38 Zeiher AM, Schachinger V, Minners J: Longterm cigarette smoking impairs endothelium-dependent coronary arterial vasodilator function. Circulation 1995;92:1094-1100.

39 Cohen J, Cohen P, Aiken L: Applied Multiple Regression/Correlation Analysis for the Behavioral Sciences, ed 3. Hillsdale, Lawrence Erlbaum Associates, 2002.

40 Meier P, Antonov J, Zbinden R, Kuhn A, Zbinden S, Gloekler S, Delorenzi M, Jaggi R, Seiler C: Non-invasive gene-expressionbased detection of well-developed collateral function in individuals with and without coronary artery disease. Heart 2009;95:900908 . 